\title{
Thermal and Mechanical Properties of Oxyfluorophosphate Glass Containing $\mathrm{Er}^{3+} / \mathbf{Y b}^{3+}$
}

\author{
S. Sobaih ${ }^{a}$, Sh. Heikal', Aly Saeed ${ }^{c}$, A.Abdelghany $^{b}$ \\ ${ }^{a}$ Mathematics and Physics Department, Faculty of Engineering, \\ Egyptian-Russian University \\ ${ }^{b}$ Physics Department, Faculty of science (Girls Branch), \\ Al-Azhar University \\ ${ }^{c}$ Nuclear Power Stations Department, Faculty of Engineering, \\ Egyptian-Russian University
}

Modified Erbium-Ytterbium co-doped oxyfluorophosphate glasses were prepared via melt quenching method. The dependence of thermal and mechanical properties on $\mathrm{Er}_{2} \mathrm{O}_{3}$ dopants were investigated. The microhardness is found to decrease with the dopant concentration due to the indentation size effect. The observed decrease of the glass transition temperature Tg with increasing dopant concentration are elucidated in terms of the bonding strength of the glass network. Increasing of $\mathrm{Er}_{2} \mathrm{O}_{3}$ changes the network structure of oxyfluorophosphate glass and improves the thermal stability. The obtained thermal and mechanical results of these $\mathrm{Er}_{2} \mathrm{O}_{3}$ added oxyfluorophosphate glasses support their applications in various technological fields.

\section{Introduction:}

Rare earth ions co-doped heavy metal oxyfluorophosphates glassy offer a great interest in many fields such as lasing medium, optical fiber amplifiers and waveguide lasers. The considerable attention given to rare earth ions co-doped heavy metal oxyfluorophosphates glassy attributed to its physical properties, like thermal, electrical and mechanical, isotropy, economy and the easy fabrication [1-3].The lower melting, glass transition and glass softening temperatures as well as the higher thermal expansion coefficient of phosphate glasses enable them to be one of the most important networks [4]. Fluoride host glasses have high quantum yield for conversion luminescence due to the ionic bond and low photon energy of fluoride [5-6]. Heavy metal glasses are excellent host materials for transition metal TM and rare earth metal ions $\mathrm{RE}^{3+}$ and have numerous practical applications in the field[7-8]. The high solubility of high concentration of rare earth, RE, oxides in metal oxyfluorophosphate glass enabled it to be one of the most suitable host networks for $\mathrm{RE}^{3+}$ ions [5-10]. 
At low ratios of phosphate/ fluoride (P/F ratios), the local environment of the $\mathrm{RE}^{3+}$ ions seem to dominate by fluoride ligation, which is important for higher emission efficiency and phonon-assisted energy transfer processes [5-10]. The poor chemical durability of phosphate glass may treat via addition of various rareearth ions, alkali and alkaline earth metal oxides [5-10].

Hence, the present work is devoted to the examination of thermal and mechanical properties of $\mathrm{P}_{2} \mathrm{O}_{5}-\mathrm{ZnO}-\mathrm{Pb}_{2} \mathrm{O}_{3}-\mathrm{WO}_{3}-\mathrm{NaF}-\mathrm{LiF}-\mathrm{Er}^{3+}-\mathrm{Yb}^{3+}$ glasses. The variations in the properties with the structural change of the glasses are also discussed.

\section{Experimental Techniques}

Proper amounts of high purity oxides and fluoride, which are listed in Table (1) were mixed and melted to prepare high-density oxyfluorophosphate glass containing $\mathrm{Er}^{3+} / \mathrm{Yb}^{3+}$. The raw materials were mixed thoroughly in an agate mortar and placed in a porcelain crucible for melting it in an electric furnace at $1100{ }^{\circ} \mathrm{C}$ for $2 \mathrm{hr}$ to obtain a homogenous bubble free liquid. During the melting period, the molten was shaked frequently then quenched on a preheated brass and annealed below the glass transition temperature to eliminate internal thermal stresses.

Table (1): Chemical composition of the studied glasses

\begin{tabular}{|c|c|c|c|c|c|c|c|c|}
\hline Glass Label & \multicolumn{7}{|c|}{ Chemical Composition } \\
\cline { 2 - 11 } & $\mathrm{P}_{2} \mathrm{O}_{5}$ & $\mathrm{ZnO}$ & $\mathrm{Pb}_{2} \mathrm{O}_{4}$ & $\mathrm{WO}_{3}$ & $\mathrm{NaF}$ & $\mathrm{LiF}$ & $\mathrm{Er}_{2} \mathrm{O}_{3}$ & $\mathrm{Yb}_{2} \mathrm{O}_{3}$ \\
\hline PFYb & 45 & 23 & 20 & 2 & 5 & 5 & 0 & 2 \\
\hline PFYb0.1Er & 45 & 23 & 17.9 & 2 & 5 & 5 & 0.1 & 2 \\
\hline PFYb0.2Er & 45 & 23 & 17.8 & 2 & 5 & 5 & 0.2 & 2 \\
\hline PFYb0.3Er & 45 & 23 & 17.7 & 2 & 5 & 5 & 0.3 & 2 \\
\hline PFYb0.4Er & 45 & 23 & 17.6 & 2 & 5 & 5 & 0.4 & 2 \\
\hline
\end{tabular}

Differential scanning calorimeter DSC measurements were carried out by TA Instruments, SDT Q600 in an open platinum pan at heating rates $10 \mathrm{~K} / \mathrm{min}$ up to higher than $600 \mathrm{C}$ in a high purity nitrogen atmosphere and at a flow rate 15 Psi. The test was performed to identify the characteristic temperatures such as the glass transition, onset of crystallization, and crystallization temperatures with accuracy $\pm 3(\mathrm{~K})$ under non isochronal conditions (constant heating rate) that are mainly used in determining the thermal parameters. The Vickers microhardness were measured by using HMV Shimadzu Micro Hardness Tester with a load with equal to $490.3 \mathrm{mN}$ by a force duration with 10 second for each sample. Five randomly indentation was tested on the same smooth surface for each sample. 


\section{Results and Discussion:}

The Differential Scanning Calorimetry (DSC) plots of the studied glasses at a heating rate $10 \mathrm{C} / \mathrm{min}$ are displayed in Fig. (1). All glasses exhibit exothermic effects attributed to the glass transition temperature $(\mathrm{Tg})$. There only one exothermic peak for the crystallization temperature $\mathrm{T}_{\mathrm{C}}$ which attributed to the nucleation processes followed by establishing of a crystalline phase of a low internal free energy $[4,11]$.

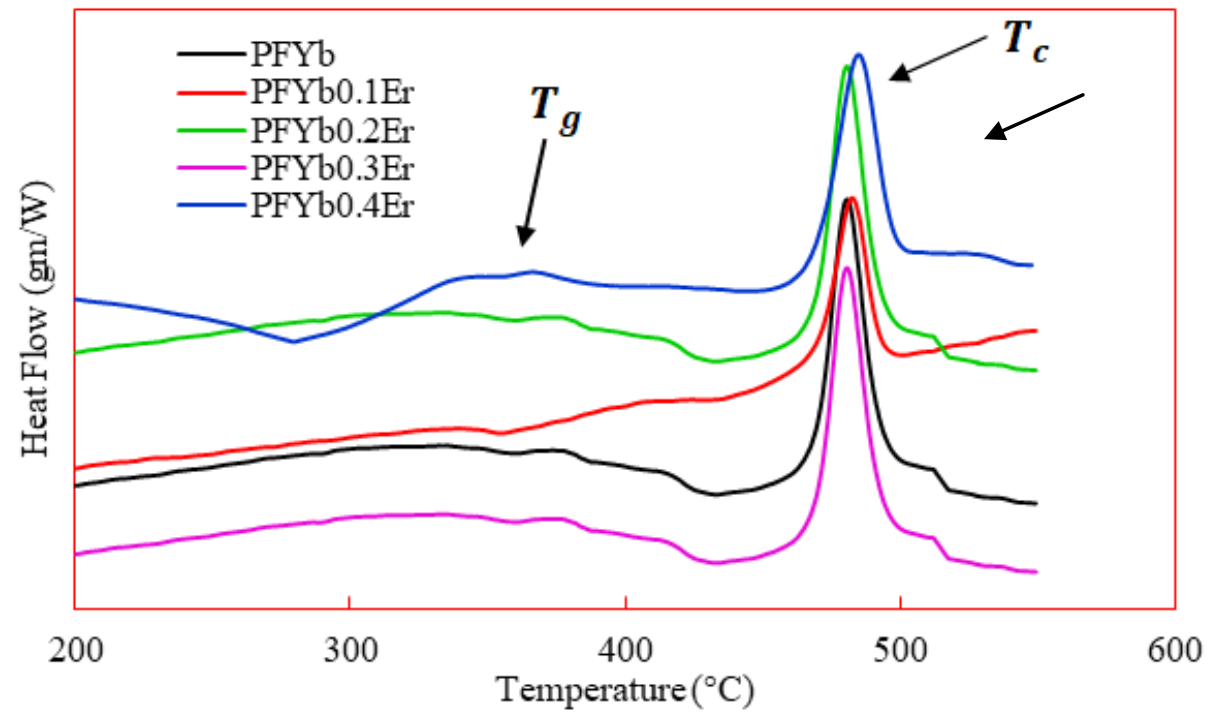

Fig 1: DSC plots of the studied glasses

Based on the obtained DSC curves the characteristic temperatures such as the glass transition $T_{g}$ and the crystallization $T_{c}$ were obtained as shown in Fig. (2). It can be obseryed that the glass transition temperature $T_{g}$ is gradually decreased from 365 to $354{ }^{\circ} \mathrm{C}$ with the increase of $\mathrm{Er}_{2} \mathrm{O}_{3}$ concentration. In the same respect the onset crystallization temperature increased from 480 to $490^{\circ} \mathrm{C}$. The obseryed decrease in $T_{g}$ indicates the decrease of bonding strength in the glass structure which in turn means the glass network somewhat less rigid[4, 11]. 


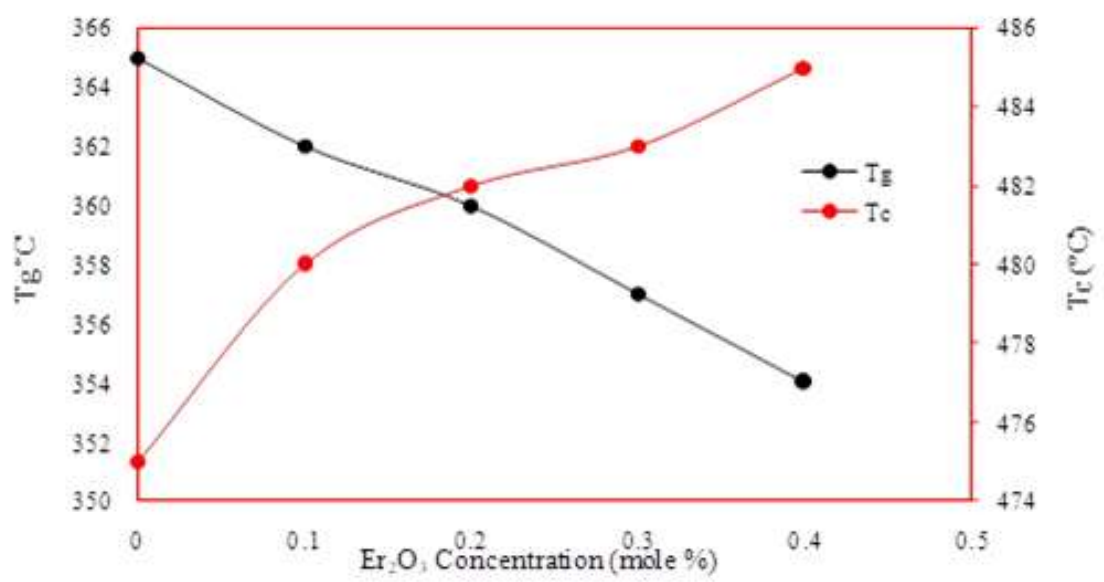

Fig (2): Variation of glass transition \& crystallization temperatures with erbium concentration.

The temperature gap between $T_{g}$ and $T_{c}$ is used as a rough measure of the glass forming ability of a melt, i.e., of resistance against crystallization during casting. The glass stability against crystallization $\Delta S$ is estimated via [11-12]

$$
\Delta S=T_{c}-T_{g}
$$

The deduced values of glass stability are shown in Fig. (3). The large value of $\Delta S$ means strong inhibition to processes of nucleationand crystallization $[4,11]$.

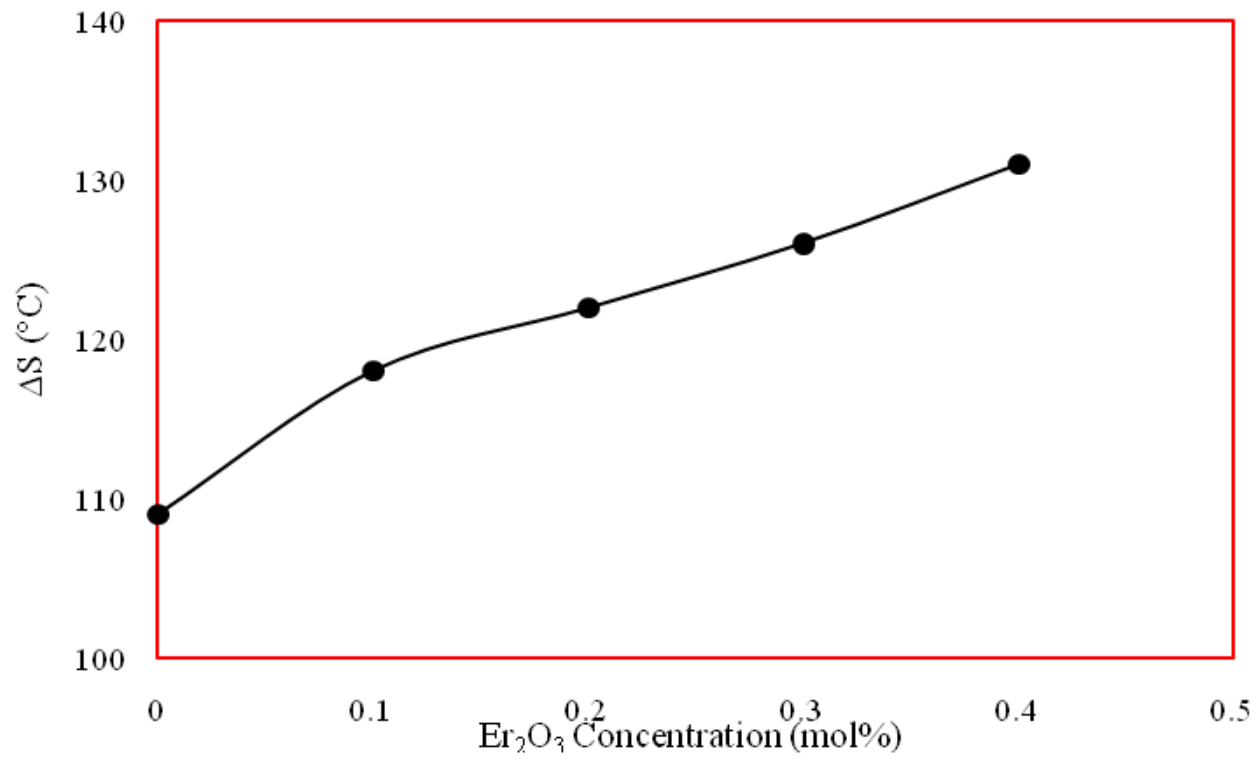

Fig (3): variation of glass thermal stability range with erbium concentration. 
The microhardness decreases with the increase of $\mathrm{Er}_{2} \mathrm{O}_{3}$ as shown in Fig. (4), due to the decrease in packing density. It means there was breaking of some $\mathrm{P}-\mathrm{O}-\mathrm{Er}$ bonds per volume in the glass network during the application of load, which led to a decrease in the resistance of deformation [13]. In the other word, the decrease of microhardness is consistent with the weakening of glass network. These results are harmonic with the glass transition temperature.

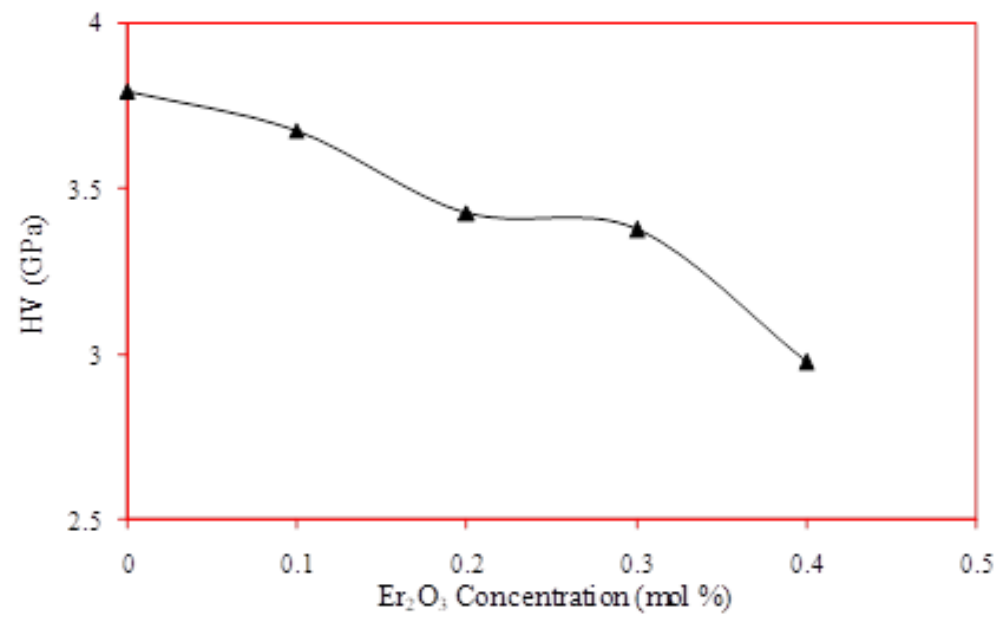

Fig (4): Variation of microhardness with erbium concentration

\section{Conclusion:}

In heavy metal oxyfluorophosphate glasses, the doping of $\mathrm{Er}_{2} \mathrm{O}_{3}$ at the expense of $\mathrm{Pb}_{2} \mathrm{O}_{4}$ leads to the decrease in the packing density which caused a decrease in microhardness. The appropriate amount of $\mathrm{Er}_{2} \mathrm{O}_{3}$ improves the thermal stability of the studied glass network. The experimental evaluation on thermal and mechanical properties of the studied heavy metal oxyfluorophosphate glasses may contribute towards the development of glass network as conversion layer for the solar cell due to their good thermal stability and suitable hardness.

\section{References}

1. F. M. Ezz ElDin, A. S. Elbayoumi, E. E. Borham, "Oxy-Fluorophosphate GlassDopedSmO ${ }^{3+}$ As SolidState Dosimeter Via Spectroscopic Techniques”, Optical and Quantum Electronics, Vol. 51: No. 275, PP. 1-13, 2019.

2. M. Naftaly and A. Jha, "Nd ${ }^{3+}$-Doped Fluoroaluminate Glasses for a $1.3 \mathrm{um}$ Amplifier, ”Journal of Applied Physics, Vol. 87, PP. 2098-2104, 2000.

3. S.E. Stokowski, W.E. Martin and S.M. Yarema, "Optical and Lasing Properties of Fluorophosphate Glass, ”Journal of Non-Crystalline Solids, Vol. 40, PP. 481-487, 1980. 
4. M. Elisaa, B. A. Savab, A. Diaconub, L. Boroicab, D. Ursub, I. Stamatinc, F. Nastasec, C. Nastasec and C. Logofatu, "Thermal Properties of Ecological Phosphate and Silicate Glasses "Glass Physics and Chemistry, Vol. 35, No. 6, PP. 596-601, 2009.

5. Mohammed Saad, "Fluoride Glass Fiber: State of The Art", Proceedings of SPIE - The International Society for Optical Engineering, Vol. 7316, PP. 116,2009

6. D. Valiev and K. Belikov, "Spectroscopic investigations of phosphateborate-fluoride glass doped with $\mathrm{Tb}^{3+} / \mathrm{Eu}^{3+}$,, Journal of Non-Crystalline Solids, Vol. 457, PP. 31-35, 2017.

7. M. A. Marzouk, S. M. Abo-Naf, H. A. Zayed and N. S. Hassan, "Glass Former Effects on Photoluminescence and Optical Properties of Some Heavy Metal Oxide Glasses Doped With Transition Metal Ions", Journal of Applied Spectroscopy, Vol. 84, No.1, PP. 162-169, 2017

8. Aly Saeed, Y. H. Elbashar and S. U. El Kameesy, "Optical Spectroscopic Analysis of HighDensity Lead Borosilicate Glasses", Silicon, Vol. 10, PP. 185-189, 2018.

9. Mohammed Saad, "Heavy Metal Fluoride Glass Fibers and Their Applications",Asia Communications and Photonics Conference and Exhibition (ACP), Vol. 8307, PP. 1-16, 2011.

10. Doris Ehrt, "Review: Phosphate and Fluoride Phosphate Optical Glasses Properties, Structure and Applications",European Journal of Glass Science and Technology Part B Physics and Chemistry of Glasses, Vol. 56, No. 6, PP. 217-234, 2015.

11. CHENG Yin, WU Zhongqing, HU Xi, WU Tengyan and ZHOU Weiwei, "Thermal Stability and Optical Properties of A Novel $\mathrm{Tm}^{3+}$ Doped Fluorotellurite Glass", Journal of Rare Earths, Vol. 32, No. 12, PP. 11541161, 2014.

12. Magdalena Lesniak , Jacek Zmojda, Marcin Kochanowicz, Piotr Miluski,Agata Baranowska, Gabriela Mach, Marta Kuwik, Joanna Pisarska, Wojciech A. Pisarski and Dominik Dorosz, "Spectroscopic Properties of Erbium-Doped Oxyfluoride Phospho-Tellurite Glass and Transparent GlassCeramic Containing BaF ${ }_{2}$ Nanocrystals", Materials, Vol. 12, PP. 1-12, 2019.

13. D. Z. Grabco, O. A. Shikimaka, M. Elisa, B. A. Sava, L. Boroica, K. Pyrtsak, A.Prisacaru, Z. Danitsa, I. Feraru, and D. Ursu, "Features of the Mechanical Properties of Phosphate Glasses Doped with Rare Earth Elements under Indentation", Surface Engineering and Applied Electrochemistry, Vol. 48, No. 4, pp. 365-374, 2012. 